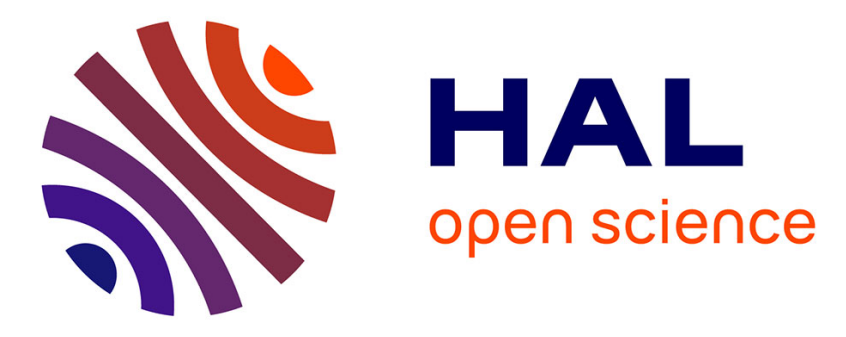

\title{
Identification of new antigen candidates for the early diagnosis of Mycobacterium avium subsp. paratuberculosis infection in goats
}

Armel Souriau, Sandrine Freret, Benjamin Foret, Peter T.J. Willemsen, Douwe Bakker, Laurence L.A. Guilloteau

\section{To cite this version:}

Armel Souriau, Sandrine Freret, Benjamin Foret, Peter T.J. Willemsen, Douwe Bakker, et al.. Identification of new antigen candidates for the early diagnosis of Mycobacterium avium subsp. paratuberculosis infection in goats. Research in Veterinary Science, 2017, 115, pp.278-287. 10.1016/j.rvsc.2017.05.025 . hal-01608409

\section{HAL Id: hal-01608409 \\ https://hal.science/hal-01608409}

Submitted on 25 May 2020

HAL is a multi-disciplinary open access archive for the deposit and dissemination of scientific research documents, whether they are published or not. The documents may come from teaching and research institutions in France or abroad, or from public or private research centers.
L'archive ouverte pluridisciplinaire HAL, est destinée au dépôt et à la diffusion de documents scientifiques de niveau recherche, publiés ou non, émanant des établissements d'enseignement et de recherche français ou étrangers, des laboratoires publics ou privés.

\section{(ㅇ)(1) $\$$}

Distributed under a Creative Commons Attribution - NonCommercial - NoDerivatives 44.0 


\section{Accepted Manuscript}

Identification of new antigen candidates for the early diagnosis of Mycobacterium avium subsp. paratuberculosis infection in goats

Armel Souriau, Sandrine Freret, Benjamin Foret, Peter T.J. Willemsen, Douwe Bakker, Laurence A. Guilloteau

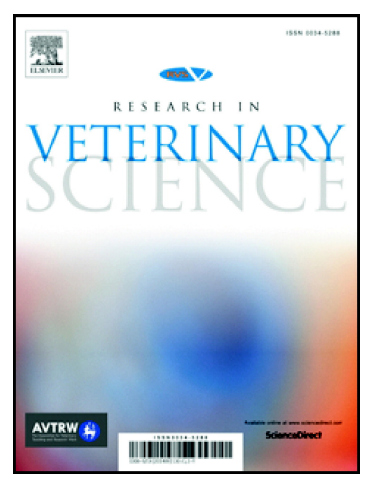

PII:

S0034-5288(17)30306-5

DOI: doi: 10.1016/j.rvsc.2017.05.025

Reference: YRVSC 3341

To appear in: Research in Veterinary Science

Received date: 14 March 2017

Revised date: 16 May 2017

Accepted date: 17 May 2017

Please cite this article as: Armel Souriau, Sandrine Freret, Benjamin Foret, Peter T.J. Willemsen, Douwe Bakker, Laurence A. Guilloteau , Identification of new antigen candidates for the early diagnosis of Mycobacterium avium subsp. paratuberculosis infection in goats, Research in Veterinary Science (2017), doi: 10.1016/j.rvsc.2017.05.025

This is a PDF file of an unedited manuscript that has been accepted for publication. As a service to our customers we are providing this early version of the manuscript. The manuscript will undergo copyediting, typesetting, and review of the resulting proof before it is published in its final form. Please note that during the production process errors may be discovered which could affect the content, and all legal disclaimers that apply to the journal pertain. 


\section{Identification of new antigen candidates for the early diagnosis of}

\section{Mycobacterium avium subsp. paratuberculosis infection in goats}

Armel Souriau ${ }^{1}$, Sandrine Freret ${ }^{2}$, Benjamin Foret ${ }^{1}$, Peter TJ Willemsen ${ }^{3}$, Douwe Bakker ${ }^{4}$ and Laurence A Guilloteau ${ }^{1 *}$

${ }^{1}$ ISP, INRA, 37380 Nouzilly, France

${ }^{2}$ PRC, CNRS, IFCE, INRA, Université de Tours, 37380 Nouzilly, France

${ }^{3}$ Department of Infection Biology, Wageningen Bioveterinary Research, 8200 AB Lelystad, The Netherlands

${ }^{4}$ Buitenplaats, 116, 8212AM, Lelystad, The Netherlands

* Corresponding author

Present address: URA, INRA, 37380 Nouzilly, France

Armel Souriau: a-souriau@ orange.fr

Sandrine Freret: Sandrine.Freret@inra.fr

Benjamin Foret: benjamin.foret@curie.fr

Peter Willemsen: Peter.Willemsen@wur.nl

Douwe Bakker: douwe.bakker@kpnmail.nl

Laurence Guilloteau: Laurence.Guilloteau@inra.fr 


\section{Abstract}

Currently Mycobacterium avium subsp. paratuberculosis (MAP) infection is diagnosed through indirect tests based on the immune response induced by the infection. The antigens commonly used in IFN- $\gamma$ release assays (IGRA) are purified protein derivative tuberculins (PPD) . However, PPDs, lack both specificity (Sp) and sensitivity (Se) in the early phase of infection. This study investigated the potential of 16 MAP recombinant proteins and five lipids to elicit the release of IFN- $\gamma$ in goats from herds with or without a history of paratuberculosis. Ten recombinant proteins were selected as potential candidates for the detection of MAP infection in young goats. They were found to detect 25 to $75 \%$ of infected shedder (IS) and infected non-shedder (INS) kids younger than 10 months of age. In comparison, PPD was shown to detect only $10 \%$ of INS and no IS kids. For seven antigens, Se (21-33\%) and Sp ( $\geq 90 \%)$ of IGRA were shown to be comparable with PPD at 20 months old. Only three antigens were suitable candidates to detect IS adult goats, although Se was lower than that obtained with PPD. In paratuberculosis-free herds, IGRA results were negative in $97 \%$ of indoor goats and $86 \%$ of outdoor goats using the 10 antigens. However, 22 to $44 \%$ of one-year-old outdoor goats were positive suggesting that they may be infected. In conclusion, this study showed that ten MAP recombinant proteins are potential candidates for early detection of MAP infected goats. Combining these antigens could form a possible set of MAP antigens to optimize the Se of caprine IGRA.

\section{Keywords}

Mycobacterium avium subsp. paratuberculosis, paratuberculosis, Johne's disease, antigen, IFN- $\gamma$, early diagnosis, goat 


\section{Highlights}

Ten MAP proteins are potential candidates for early detection of MAP infected goats.

\section{Introduction}

Paratuberculosis is a chronic intestinal inflammation of ruminants caused by Mycobacterium avium subsp. paratuberculosis (MAP). Contamination by MAP generally occurs during the first months of life through the faecal-oral route or by ingestion of contaminated milk, or even in utero (Biet et al., 2005). MAP infection can give rise to a subclinical form of the disease for several years before progressing to a clinical form associated with diarrhoea, weight loss, decreased milk production and cachexia. The clinical form of MAP infection can affect animal welfare and health, and result in economic losses through decreased milk yield and premature culling (Nielsen and Toft, 2008). MAP is an intracellular bacterium which stimulates cell-mediated immunity in the first line of defence of the host mainly through the production of IFN- $\gamma$ by T helper 1 (Th1) lymphocytes. A specific antibody response will develop later and usually reflects the circulation of higher numbers of mycobacteria within the organism in an extracellular form (Arsenault et al., 2014; Stabel, 2000). Faecal shedding of MAP can occur throughout the infection process but is observed much more frequently and intensively when an antibody response has developed (Ganusov et al., 2015). Mechanisms driving the Th1/Th2 switch remain poorly understood but novel mathematical modelling of the immune response to MAP infection can help identify bacterial and host factors that contribute to this switch (Magombedze et al., 2015).

Diagnosis of MAP infection is based on the direct detection of MAP in biological samples and indirect tests analysing the immune response induced by the infection (Nielsen and Toft, 2008; Whittington and Sergeant, 2001). Even though the detection of MAP excretion in faeces is considered as the gold standard for the diagnosis of this infection, IFN- $\gamma$ production 
is an interesting immune indicator usually used for the early detection of MAP-infected animals (Stabel, 1996). Furthermore, current serological diagnostic tests for MAP infection are limited by their sensitivity (Se) when used in sub-clinical stages of the disease (Nielsen and Toft, 2008).

To measure the specific IFN- $\gamma$ production induced by MAP, antigens have to be used to stimulate in vitro blood cells and to induce IFN- $\gamma$ secretion. The antigen commonly used for this IFN- $\gamma$ release assay (IGRA) is Johnin purified protein derivative (PPDj), which is a complex crude extract of MAP antigens prepared through non-standardized protocols in different laboratories (Jungersen et al., 2002). PPDj is known to have common antigens with environmental mycobacteria such as M. avium subsp. avium (MAA) and pathogenic mycobacteria such as $M$. bovis, leading to a lack of specificity $(\mathrm{Sp})$ of the immune response to MAP (Nielsen and Toft, 2008; Osterstock et al., 2007). Nevertheless, false positive responses in IGRA are less frequent in young goats than in young cattle (Storset et al., 2005). The number of conserved immunogenic proteins was found to be more abundant in PPDj than in MAA PPD (PPDa) (Wynne et al., 2012). Standardizing and harmonizing the protocol of PPDj production and use would increase the reproducibility and Sp of IGRA.

Numerous studies have investigated the use of defined MAP antigens to improve the Se and Sp of IGRA for diagnosing MAP infection. Different approaches have been used to identify, produce and evaluate MAP antigens for their potential use in the diagnosis of MAP infection in cattle (Mikkelsen et al., 2011) and in sheep (Gurung et al., 2012b; Gurung et al., 2014; Hughes et al., 2013). A few studies have investigated the potential of MAP antigens for the serodiagnosis of MAP infection in goats (Casey et al., 2011; Pradenas et al., 2009) but not for IGRA. Our study thus investigated the potential of different MAP recombinant proteins and lipids to elicit IFN- $\gamma$ production in goats from herds with or without a history of paratuberculosis. Our aims were i) to screen the potential of 21 antigens in IGRA in MAP 
exposed goats, ii) to test their ability to discriminate between infected and shedder (IS), infected and non-shedder (INS), and non-infected (NI) goats, iii) to test their ability to detect early-stage infection in goats.

\section{Materials and Methods}

\subsection{Animals and protocol design for antigen assessment}

The animals included in this study came from private farms, they underwent no specific experimentation. Consequently, this study did not require an ethics committee authorization. Dairy goats (Alpine breed) from a herd naturally exposed to MAP (France) were used to define the MAP infection status and to screen for MAP antigens in IGRA. The status of MAP infection in the goats was precisely evaluated for 26 months as described previously (Mercier et al, 2016) by direct diagnosis and indirect tests, in naturally exposed kids $(n=48)$ and adult goats $(n=23)$. Direct MAP detection was performed through culture of samples of faeces and tissue (for culled animals) on Herrold's egg yolk medium supplemented with mycobactin, and Ziehl-Neelsen staining of tissues. Indirect diagnosis was performed both by serology and IFN- $\gamma$ response to PPDa. Goats were classified into the following classes of infection status: non-infected (NI), infected and non-shedder (INS), infected and shedder (IS), and atypical (A) (Table 1). Atypical goats were positive for MAP using faecal or tissue culture but showed no specific immune response during the study period. Infected goats, shedders and nonshedders, represented $66 \%$ of the goats studied. For the screening of these antigens, only NI, INS and IS goats (45/48 kids; 20/23 adults) were used (Table 2). Kids were tested monthly from 4 months of age for 19 months including a pregnancy, and 2 year-old goats were tested monthly for 7 months including their second pregnancy.

Moreover, goats from two paratuberculosis-free herds were also tested with MAP antigens. This involved 1- to 6-year-old Norwegian outdoor goats $(\mathrm{n}=36)$ and 1- to 11-year-old French 
indoor goats $(n=30)$. The status of goats was defined by the absence of clinical signs, a negative serological response and a negative IFN- $\gamma$ response to PPDa based on the use of commercial kits, but with no data on MAP shedding.

\subsection{MAP antigens}

This study investigated 21 MAP antigens, 16 protein and 5 lipid antigens, as potential antigens for diagnosing MAP infection through IGRA, using PPDa and PPDj for comparison. Out of a larger group of recombinant proteins tested in the serodiagnosis of MAP infection (Mon et al., 2012), 16 recombinant proteins were selected based on in silico analysis. These antigens were tested in IFN- $\gamma$ positive $(n=23)$ and IFN $-\gamma$ negative $(n=15)$ adult goats from a naturally infected herd tested one to three times with these antigens (data not shown). In addition, five lipid antigens were included in the antigen panel (Table 3). The 16 proteins were produced as recombinant proteins after cloning and purification largely as described previously (Willemsen et al., 2006). Briefly, they were PCR-cloned using 5'- and 3'-primers amplifying DNA fragments encoding the mature protein, except for secreted proteins, which were cloned without the signal peptide. The DNA fragments were cloned into expression vectors. All the antigens were cloned into pET33b vector (Novagen®, Darmstadt, Germany) using E. coli BL21 (DE3) as the host strain, except for the secreted Map0210c antigen described in (Willemsen et al., 2006) which was cloned in pQE80 vector (Qiagen, Venlo, Netherlands). Antigens were purified using their histidine-tagged $\mathrm{N}$-terminal region and Nickel-affinity columns (1 mL HisTrap HP columns) (GE Healthcare Life Sciences, Diegem, Belgium). Prior to this, recombinant antigen was solubilized using a buffer containing $6 \mathrm{M}$ Guanidine, $20 \mathrm{mM}$ Tris (pH 8.0), $0.5 \mathrm{M} \mathrm{NaCl}, 25$ (pQE80) or 50 (pET) mM Imidazol, $0.25 \%$ CHAPS, $1 \mathrm{mM}$ DTT, $0.5 \mathrm{mM}$ PMSF and 1\% iso-propanol in order to dissolve proteins from inclusion bodies (Guanidine), reduce non-specific binding (Imidazol) and decrease the 
amount of LPS (iso-propanol). After affinity-purification the antigens were dialysed (using a cut-off $10 \mathrm{kDa}$ except for Map4000c for which a $1 \mathrm{kDa}$ cut-off was used) against a buffer containing 0 to $6 \mathrm{M}$ Urea, $10 \mathrm{mM}$ Tris (pH 8.0), 25\% glycerol, $1 \mathrm{mM}$ DTT, $0.5 \mathrm{mM}$ PMSF, $1 \%$ iso-propanol or 0 to $7 \mathrm{M}$ Urea, $10 \mathrm{mM}$ Tris ( $\mathrm{pH} 8.0), 10 \%$ glycerol, $1 \mathrm{mM}$ DTT, $0.5 \mathrm{mM}$ PMSF, and 1\% iso-propanol. The urea concentration was the minimal concentration needed to keep the proteins solubilized and was determined empirically. Lipid antigens were purified according to protocols previously described for LOS and DAT (Daffe et al., 1989 and Papa et al., 1993), Para-LP-01 and its carboxylic acid version LPx (Eckstein et al., 2006), and GPL4 (Khoo et al., 1999).

MAP antigens were prepared at $100 \mu \mathrm{g} / \mathrm{mL}$ diluted in PBS for recombinant proteins or at 10 to $20 \mu \mathrm{g} / \mathrm{mL}$ for lipid antigens, and distributed $(25 \mu \mathrm{L} /$ well) in flat-bottom 96-well plates (Falcon 353072, Butcher, Brumath, France). PPDa $\left(300 \mu \mathrm{g} / \mathrm{mL}\right.$, Bovigam ${ }^{\circledR}$, AES, Bruz, France) and PPDj $(100 \mu \mathrm{g} / \mathrm{mL}$, National Veterinary Institute, Norway) were added to the antigen panel as reference antigens, and PBS without antigen was used as the unstimulated condition. Plates were stored at $-80^{\circ} \mathrm{C}$.

\subsection{IGRA and IFN- $\gamma$ ELISA}

Blood samples were collected in sodium heparin Vacutainer ${ }^{\circledR}$ tubes and used for IGRA within $2 \mathrm{~h}$ of collection. Briefly, plates containing antigens were thawed and $200 \mu \mathrm{L}$ of blood added per well and mixed. In accordance with previous studies (Gurung et al, 2014;

Thirunavukkarasu et al, 2013), final concentrations of antigens were $10 \mu \mathrm{g} / \mathrm{mL}$ for recombinant proteins, and $1-2 \mu \mathrm{g} / \mathrm{mL}$ for lipids. Plates were incubated for $24 \mathrm{~h}$ at $37^{\circ} \mathrm{C}$ with $5 \% \mathrm{CO}_{2}$ and then centrifuged at $1500 \mathrm{~g}$ for $20 \mathrm{~min}$ at room temperature. Plasma was collected and stored at $-80^{\circ} \mathrm{C}$. 
IFN $-\gamma$ production was assayed using ELISA, either with a bovine IFN- $\gamma$ kit according to the manufacturer's instructions (Bovine IFN- $\gamma$ EASIA, Invitrogen, Eragny sur Oise, France) or using monoclonal antibodies (mAbs) developed against bovine IFN- $\gamma$ and adapted from a protocol previously described in sheep (Olivier et al., 2012) with commercial reagents (IDvet, Montpellier, France). Briefly, plates (ID-vet) were coated with the capture anti-IFN- $\gamma$

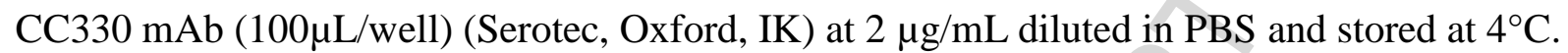
Dilution buffer (ID-vet) $(50 \mu \mathrm{L} /$ well) and plasma or recombinant IFN- $\gamma(50 \mu \mathrm{L} /$ well $)$ were added, mixed for $5 \mathrm{~min}$ and incubated at room temperature for $60 \mathrm{~min}$. Washes with washing buffer (ID-vet) were repeated between each successive step. The anti-IFN- $\gamma$ :biotinconjugated CC302 mAb (Serotec) was added (100 $\mu \mathrm{L} /$ well) at $0.5 \mu \mathrm{g} / \mathrm{mL}$ in dilution buffer and incubated at room temperature for $60 \mathrm{~min}$. Plates were then incubated with horseradish peroxidase-conjugated extravidin (E2886, Sigma-Aldrich) $(100 \mu \mathrm{L} /$ well) diluted at $1 / 1500$ in dilution buffer. The peroxidase activity was revealed at room temperature by adding tetramethyl benzidine substrate (TMB) and stopped with stop solution (ID-Vet). Absorbance was read at $450 \mathrm{~nm}$. Recombinant ovine IFN- $\gamma$ (kindly provided by Dr S. Wattegedera, MRI, Scotland) at $20 \mathrm{U} / \mathrm{mL}$ was used as a positive control. The net absorbance value was calculated for all samples by subtracting the negative control absorbance from the sample absorbance. Specific sample absorbance was then calculated for each sample by subtracting the net absorbance value for the well receiving blood samples stimulated with antigen from the net absorbance value for the well receiving unstimulated blood samples incubated with PBS. Results were expressed as an index of positivity calculated as follows:

$\%$ positivity $=($ specific sample absorbance/net positive control absorbance $) \times 100$ Se and Sp were calculated by using the number of true positives (TP), true negatives (TN), false positives (FP) and false negatives (FN) as follows:

$$
\mathrm{Se}=\mathrm{TP} / \mathrm{TP}+\mathrm{FN}
$$




$$
\mathrm{Sp}=\mathrm{TN} / \mathrm{FP}+\mathrm{TN}
$$

Positive and negative predictive values were also calculated as follows:

$$
\begin{aligned}
& \mathrm{PPV}=\mathrm{TP} / \mathrm{TP}+\mathrm{FP} \\
& \mathrm{NPV}=\mathrm{TN} / \mathrm{TN}+\mathrm{FN}
\end{aligned}
$$

TP and TN were defined as infected (both INS and IS) and non-infected (NI) goats according to the MAP infection status defined for each goat (Mercier et al, 2016).

\subsection{Statistical analyses}

Pearson correlation coefficients were calculated using the CORR procedure and Kappa coefficients of agreement were calculated using the FREQ procedure of the SAS® software (SAS Institute Inc. 2011).

\section{Results}

\subsection{IFN- $\gamma$ ELISA setting}

We developed an IFN- $\gamma$ ELISA using bovine monoclonal antibodies and commercial buffers to optimize the detection of caprine IFN- $\gamma$ in plasma, and PPDa or PPDj as reference stimulating antigens in IGRA. We compared IFN- $\gamma$ responses in young and adult goats using this ELISA and the commercial bovine IFN- $\gamma$ EASIA kit. A very significant correlation was observed between values $(n=907)$ obtained with PPDa as the antigen in the laboratory and the commercial ELISA $(p<0.0001)$ with $r^{2}=0.5775$. Higher IFN- $\gamma$ values were obtained with the in-house developed ELISA than those obtained with the commercial ELISA, particularly for values below $300 \%$ positivity without an increase in negative control values. This was in line with our objective to increase the detection of caprine IFN- $\gamma$ by developing an in-house IFN- $\gamma$ ELISA. The correlation was very significant $(p<0.0001)$ with $r^{2}=0.8035$ when PPDa and PPDj antigens were used in the laboratory ELISA $(n=972)$ (Figure 1). 
Percentages of positivity over $20 \%$ were considered as positive responses using the bovine IFN- $\gamma$ EASIA. The kappa coefficient between this commercial ELISA and the laboratory ELISA was maximal when the $50 \%$ threshold was used for the latter $(\mathrm{K}=0.6635,95 \% \mathrm{CI}$ $0.6039 ; 0.7231, \mathrm{n}=926)$. The kappa coefficient between the PPDa and PPDj antigens used in the laboratory ELISA was maximal using the $100 \%$ and 50\% threshold for PPDa and PPDj respectively $(\mathrm{K}=0.7512,95 \% \mathrm{CI} 0.6879 ; 0.8145, \mathrm{n}=993)$. We therefore used the in-house ELISA with these two reference antigens and these thresholds for the following analysis of the goat IFN- $\gamma$ response to MAP antigens.

\subsection{Evaluation of MAP antigens for IFN- $\gamma$ response in young goats}

Forty five young goats with a known MAP infection status (Table 2) were tested monthly from 4 months of age for 19 months, including a pregnancy ( 8 to 12 months old) for IFN- $\gamma$ response to the MAP antigens used in this study (Table 3). A threshold of 50, 75 or $100 \%$ positivity was defined for each antigen to be considered as a positive response. After one year of testing the 21 MAP antigens on goat blood cells, eight antigens, including Map2167c, Map0211, Map2513c and the five lipid antigens, were not tested further due to their low ability to elicit IFN- $\gamma$ production in the blood cells of infected goats (IS and INS), and under $10 \%$ of positive animals with a $50 \%$ threshold (Table 3 ).

PPDa and PPDj used as reference antigens allowed both one-year-old IS and INS goats to be detected at the time when MAP shedding was detected (data not shown). At 8 months old, $10 \%$ of IFN- $\gamma$ positive INS goats but no IS goats were detected and they all tested negative during pregnancy. A first peak of IFN- $\gamma$ positive INS and IS goats was detected at 14 months old, i.e. two months post-partum. During the study, a maximum of $37 \%$ of the IFN- $\gamma$ positive INS goats were detected with the reference antigens, whereas $100 \%$ of the IS goats were tested IFN- $\gamma$ positive at 19 months old (7 months post-partum) (Figure 2). 
The 13 selected MAP antigens were tested for their ability to induce IFN- $\gamma$ production in NI, INS and IS goats. Based on the number of animals exhibiting a positive response and the magnitude of the response, data were then only analysed on 10 antigens, Map0209c, Map1693 and Map1889c were considered to be of little interest. The number of positive animals showed substantial variation during the 19 months of the study, indicating individual variation in their IFN- $\gamma$ responses (Figure 3).

Se and Sp were calculated for each antigen including PPDa and PPDj as reference antigens. For the initial stage of the study (6 month-old goats) PPDa and PPDj were unable to detect any positive goats. On the other hand, Map1653 and Map1589c provided the highest Se (47 to $50 \%$ ) but the lowest $\mathrm{Sp}(45 \%)$ compared to the other antigens (Figure 4). The other antigens provided between 12 and 32\% Se in this period, while Map0210c provided 82 to $91 \% \mathrm{Sp}$. Map3527, Map2020, Map4000c, Map3936, Map3651c, Map1050c showed the most efficient detection of infected kids during this period, and they were able to detect $50 \%$ of IS kids (2/4). Using these antigens, the PPV for a goat to be infected by MAP, when the IFN- $\gamma$ response was positive, was between 83 and $92 \%$, whereas the NPV for a goat not to be infected by MAP when the IFN- $\gamma$ response was negative was between 25 to $30 \%$. The PPV to predict that a kid would become an IS goat was $67 \%$ and the NPV to predict that a kid would not be an IS goat was 83\%. The antigens Map1050c, and Map0210c and to a lesser extent Map3840 preferentially detected IS than INS kids.

Later in the study (20-month-old goats), the Se of IGRA using Map3840, Map3936 and Map4000c was lower than 6\%, while the other antigens allowed a Se of between 21 and 33\% and a Sp of $\geq 90 \%$ to be obtained, a level similar to that of PPDa and PPDj (Se $=27 \%$ to $36 \% ; \mathrm{Sp}=90 \%$ ). The VPP and NPV to predict infected and non-infected goats by testing IGRA with these antigens were $91 \%$ to $100 \%$, and $24 \%$ to $29 \%$ respectively, also similar to those obtained with PPDa and PPDj (VPP = 90 - 92\% ; NPV = 27 - 30\%). Map3527, 
Map1050c and Map3651c were the most effective antigens to detect IS goats during this period $(\mathrm{Se}=75-100 \% ; \mathrm{Sp}=90-100 \% ; \mathrm{VPP}=75-100 \% ; \mathrm{NPV}=90-100 \%)$. The IFN $-\gamma$ positive IS goats detected at 6 months old with these antigens (2/4) were the same as at 19 months old, the intensity of their IFN- $\gamma$ response was between 53 and $203 \%$ positivity at 6 months old. Of the IFN- $\gamma$ positive INS goats at 14 months of age, 45 to $83 \%$ (5 to 15 goats) were already detected by Map3527 and Map2020 at 8 months old.

Overall, most of the 10 antigens tested are potential candidates for detecting MAP infection in young goats (< two years old), with Map3651c and Map1050c being promising candidates for the detection of IS goats (Table 4).

\subsection{Evaluation of MAP antigens for IFN- $\gamma$ response in adult goats}

The 10 selected MAP antigens were also tested monthly in infected 2-year-old goats $(n=20)$ for 7 months during the second pregnancy and 2 months post-partum. There was no significant difference between the numbers of positive goats detected at these different sample times for any of the tested antigens or reference PPD antigens. The Se of IGRA using PPDj varied between $31 \%$ and $64 \%$ for infected goats (50 to $100 \%$ for IS goats), and was always higher than the IFN- $\gamma$ response using PPDa. The Se of the test with PPDj tended to decrease during pregnancy preserving a Sp of between 80 and 100\% (data not shown). The analysis focusing on the first month of pregnancy showed that three of the ten antigens tested were able to detect the maximum number of infected goats. Se for IS goat detection was $50 \%$ using Map3651c and Map2020, and 25\% with Map3840, compared to 75\% with PPDj (Figure 5). The former two antigens provided a detection Se of only $10 \%$ for the INS goats, while Map3840 did not detect any. Sp of these antigens was 83\% compared to $100 \%$ with PPDj. The 10 MAP antigens tested individually in adult goats ( $>2$ years old) were limited in their potential for MAP diagnosis. The three antigens Map3651c, Map2020 and Map3840, are 
possible candidates to detect infected goats, particularly IS goats. Map3651c shows the greatest potential (Table 4).

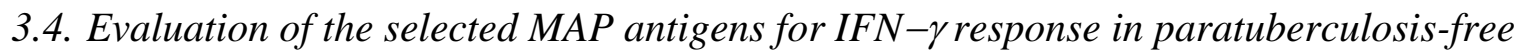
goats

The Sp of MAP antigens were assessed in paratuberculosis-free goats from an indoor and an outdoor herd. For the indoor herd, 97\% of the goats tested with our IFN- $\gamma$ ELISA using PPDj were negative, and $83 \%$ to $100 \%$ of the goats were negative using selected MAP antigens. For the outdoor herd, $86 \%$ of the goats were negative with PPDj and $56 \%$ to $89 \%$ with the other antigens (Figure 6). In one-year-old outdoor goats, $17 \%$ of them were IFN- $\gamma$ positive with PPDj and 28\% to 44\% were detected positive using Map3527, Map2020, Map3651c and Map1050c. In older goats, $11 \%$ of them were IFN $-\gamma$ positive with PPDj and 17\% were detected positive using Map3527, Map2020 and Map1050c. Without further complementary data on the MAP infection status of these goats, particularly MAP shedding, these IFN- $\gamma$ positive goats could have been either IS or INS which until then had remained undetected by commercial kits.

\section{Discussion}

The early detection of MAP infection in goat herds, essential for controlling infection in a herd is a major challenge. Early detection of infected animals would allow timely removal of future shedders and thus reduce the transmission of infection within a herd. The detection of MAP shedding in faeces or tissue by mycobacteria culture is considered as the gold standard method for the diagnosis of MAP infection but has significant limitations. Culture is labour intensive, requires long incubation periods and the intermittent excretion of MAP contributes to a great uncertainty regarding the actual infection status of the animals. Diagnosis of MAP 
infection in goats using PPDj as the antigen in the IGRA has been shown to provide earlier detection than using faecal culture (Lybeck et al, 2011; Mercier et al, 2016). It has also limitations because PPDj lacks Sp to MAP, has a low Se in the early stage of infection and its preparation protocols result in a poorly standardized and ill-defined mixture of antigens. An IGRA using PPDa and PPDj in combination with the in-house IFN- $\gamma$ ELISA developed in this study allowed detection of a first peak of infected goats at one year of age when detection of MAP shedding started, followed by a second peak of positive goats 2 months post-partum (14 months old), and a maximum of 37\% INS goats and 100\% IS goats 7 months post-partum (19 months old). Similar periods for both positive IFN- $\gamma$ response and MAP shedding were also observed when the commercial bovine IFN- $\gamma$ kit was used (Mercier et al, 2016; Lybeck et al., 2011). Despite the low Se of PPDa and PPDj for IGRA in young goats, $10 \%$ of INS kids were detected at 8 months old, but no IS kids, suggesting that INS kids could produce an early IFN- $\gamma$ response which could contribute to a later control of MAP shedding.

A strategy using recombinant antigens would be suitable for preparing a standardized welldefined combination of antigens provided that this combination elicited a suitable $\mathrm{Sp}$ and $\mathrm{Se}$ in the IGRA for the detection of MAP infection. This study investigated the potential of 21 MAP antigens, 16 recombinant proteins and five lipids, to elicit an IFN- $\gamma$ response in goats defined for their MAP infection status (Mercier et al, 2016). Among the 13 MAP antigens selected during the study, 10 were found to detect 25 to $75 \%$ of infected goats between 6 and 10 months old. For this age range, the maximal Se (47-50\%) was obtained with Map1653 and Map1589c, but with a low Sp (45\%). Although Map1589c (AhpC) is expressed by MAP and not by other mycobacterial species, this protein did not specifically allow early detection of infected kids through IGRA, whereas it was possible to detect MAP infected cattle with the antibody response (Olsen et al., 2001). Although a higher Se of IGRA was obtained with Map1653 and Map1589c, the lower Sp would result in too many false positives which is 
unacceptable. This low Sp is probably related to a non-specific induction of IFN- $\gamma$ release by these two proteins in young goats, possibly by NK cells. Considerably higher Se of IGRA was obtained using Map3527, Map2020, Map4000c, Map3936, Map3651c, Map1050c (12 to $32 \%$ ) than using PPD. The potential of these antigens to predict that a positive goat would become infected later (PPV between 83 and 92\%), and that a negative goat would not become an IS goat later (NPV 83\%) was good.

It is of interest to note that Map1050c, Map0210c and Map3840 preferentially detected early IS goats rather than INS goats. Map1050c is a PpiB isomerase which belongs to the cyclophilin family. Eucaryotic cyclophilin B has been reported to play a role in attenuating the macrophage inflammatory response (Marcant et al., 2012) suggesting that MAP could use this protein to resist the process of phagocytosis. Map0210c is a secreted PirG protein shown to be a cell surface-exposed protein expressed by Mycobacteria during residence in the phagosomes of in vitro-maintained macrophages (Berthet et al., 1998). Map3840 is the heat shock protein DnaK, a stress protein expressed in response to environmental stimuli encountered in the infected host (Patel et al., 1991). The immune response towards these proteins resulting in IFN- $\gamma$ production, particularly in shedder goats, supports the fact that the host is attempting to limit the progression of MAP infection.

In 20 month-old goats (7 months post-partum), Se and Sp obtained with seven of the ten antigens (excepting Map3840, Map3936 and Map4000c) were relatively similar to those obtained with PPD. The antigens Map1050c, Map3527 and Map3651c allowed IS goats to be detected preferentially. In silico identification of immune epitopes on recombinant MAP proteins upregulated under stress conditions showed that MHC class I T-cell and B-cell epitopes were identified in Map3651c and represent a potential for MAP infection diagnosis (Gurung et al., 2012a). Unfortunately, Map3651c was not included in further analyses for serodiagnosis (Gurung et al., 2012b) or IGRA (Gurung et al., 2014) in ovine paratuberculosis, 
but it was selected in other studies investigating IFN- $\gamma$ production in the subclinical-stage of MAP infected sheep (Hughes et al., 2013). Map3651c (FadE3_2) is an enzyme involved in electron transport with acylCoA dehydrogenase activity, and is linked to the $\beta$-oxidation pathway of fatty acids, which can be used as a carbon source and may contribute to mycobacterial replication, particularly within host macrophages. Map3527 is a serine protease (PepA) assumed to be essential for in vivo survival and pathogenicity of Mycobacteria (Ribeiro-Guimaraes and Pessolani, 2007).

Overall, most of the 10 MAP antigens tested are potential candidates for the detection of MAP infected young goats ( $<2$ years old), two of them, Map3651c and Map1050c could be candidates for the early detection of future IS goats.

In goats older than 2 years of age, only three of the ten antigens tested were able to detect infected goats, Map3651c, Map2020 and Map3840. Se obtained with these antigens was lower than that obtained with PPDj (maximum 50\% vs 75\%), thus their potential for MAP diagnosis is limited when used individually. On the other hand, combining these antigens could enhance Se while preserving a high Sp.

The five lipids were not found to elicit IFN- $\gamma$ production in infected goats or non-specific responses in non-infected goats. The MAP-specific synthetic lipopeptide Para-LP-01 could be a suitable candidate for specific diagnosis of MAP infection, but under our conditions it failed to induce detectable IFN- $\gamma$ production in goat blood cells as reported in sheep (Thirunavukkarasu et al., 2013). Even though IFN- $\gamma$ production induced by the lipopeptide L5P was detected in MAP infected cattle, the level of production was low and did not enable a specific status of animals to be defined (Holbert et al., 2015). Mycobacterial lipid antigens are presented to T-cells through specific CD1 molecules (De Libero and Mori, 2014). This process might be more difficult to perform in in vitro assays with whole blood than when protein antigens are presented to T-cells via classical MHC molecules. In addition, the 
concentration of lipid antigens might not be optimized for in vitro assay as suggested previously (Thirunavukkarasu et al, 2013). Another reason to explain why lipid antigens failed to induce IFN- $\gamma$ production could be related to their important role as cofactors in MAP pathogenesis. For example, DAT and GPLs have been shown to inhibit Th1-cytokine responses (Palma-Nicolas et al, 2010; Mukherjee and Chatterji, 2012).

Although Se and Sp of IGRA obtained with the ten MAP antigens were relatively similar or better to those obtained with PPD before 2 years of age in MAP infected goats, it is important to test the Sp of IGRA using these antigens in paratuberculosis-free goat herds. IGRA using the new MAP antigens showed that 83 to $100 \%$ of indoor goats were negative, whereas only 56 to $89 \%$ of outdoor goats were negative. In outdoor goats, the highest proportion positive for IFN- $\gamma$ was in one-year-old goats using Map3527, Map2020, Map3651c and Map1050c. These antigens correspond to the MAP antigens showing a good potential for early diagnosis of infected, particularly IS goats, with Map3651c and Map1050c. One-year-old indoor goats were also IFN- $\gamma$ positive using these antigens and Map0210c $(n=4)$. In the absence of MAP shedding data in these goats, we can only suggest that these IFN- $\gamma$ positive goats could have been infected and could become future shedders.

In conclusion, even though these results were obtained in a limited number of goats, they show that MAP recombinant proteins have a potential for the early detection of MAP infected goats (< one year old),. However, they were limited in their potential for MAP diagnosis in adult goats compared to PPDj. Combining Map3527, Map2020, Map3651c, Map1050c, Map0210c and Map4000c could form a possible set of MAP antigens to optimize the Se of caprine IGRA. These antigens should be investigated further in a larger sample of goats from both MAP infected and MAP free herds to strengthen these results and to evaluate their predictive values for the detection of early shedder infected goats. The Sp of caprine IGRA should also be investigated in M. bovis infected goats using these antigens. 


\section{List of abbreviations}

CMI: Cell-mediated immunity; ELISA: Enzyme linked immunosorbent assay; IFN- $\gamma$ : Gamma interferon; IGRA: Gamma interferon release assay; IS: Infected and shedder; INS: Infected and non-shedder; MAP: Mycobacterium avium subspecies paratuberculosis; NI: Noninfected; PPDa: Purified Protein Derivative from Mycobacterium avium subspecies avium; PPDj : Johnin purified protein derivative; Se: Sensitivity; Sp: Specificity; PPV: Positive predictive values; NPV: Negative predictive values.

\section{Competing interests}

The authors declare that they have no competing interests

\section{Author details}

${ }^{1}$ ISP, INRA, 37380 Nouzilly, France

${ }^{2}$ PRC, CNRS, IFCE, INRA, Université de Tours, 37380 Nouzilly, France

${ }^{3}$ Department of Infection Biology, Wageningen Bioveterinary Research, 8200 AB Lelystad, The Netherlands

${ }^{4}$ Buitenplaats, 116, 8212AM, Lelystad, The Netherlands

\section{Authors' contributions}

LG conceived and supervised the study, and wrote the manuscript; AS and BF contributed to the study design, conducted the experiments and collected the data; SF performed statistical analyses; PW and DW prepared MAP antigens and participated in the discussions. All authors read and approved the final manuscript. 


\section{Acknowledgements}

The authors thank H. Coutineau (LEGTA, Melle, France) and breeders for their interest and their involvement in this project, K. Laroucau (ANSES, Maisons Alfort) and P. Mercier (ANSES, Niort) for their constructive discussion during the study. They are grateful to I. Olsen (NVI, Oslo, Norway) for providing PPDj, S. Wattergedera for providing recombinant ovine IFN- $\gamma$ developed by the Immunological Toolbox funded by a collaborative BBSRC/SEERAD programme, ID-VET (Montpellier, France) for providing reagents and materials for antigen coating and the IFN- $\gamma$ ELISA. This work was funded by the European Commission (Sixth Framework Programme) in the ParaTB Tools project, FOOD-CT-2006023106. B. Foret was funded by this grant. The English was reviewed by S. Edrich (Inter Connect LC - Language Coaching). 


\section{References}

Arsenault, R.J., Maattanen, P., Daigle, J., Potter, A., Griebel, P., Napper, S., 2014. From mouth to macrophage: mechanisms of innate immune subversion by Mycobacterium avium subsp. paratuberculosis. Vet. Res. 45, 54.

Berthet, F.X., Lagranderie, M., Gounon, P., Laurent-Winter, C., Ensergueix, D., Chavarot, P., Thouron, F., Maranghi, E., Pelicic, V., Portnoi, D., Marchal, G., Gicquel, B., 1998. Attenuation of virulence by disruption of the Mycobacterium tuberculosis erp gene. Science 282, 759-762.

Biet, F., Boschiroli, M.L., Thorel, M.F., Guilloteau, L.A., 2005. Zoonotic aspects of Mycobacterium bovis and Mycobacterium avium-intracellulare complex (MAC). Vet. Res. 36, 411-436.

Casey, J.L., Sanalla, A.M., Tamvakis, D., Thalmann, C., Carroll, E.L., Parisi, K., Coley, A.M., Stewart, D.J., Vaughan, J.A., Michalski, W.P., Luke, R., Foley, M., 2011. Peptides specific for Mycobacterium avium subspecies paratuberculosis infection: diagnostic potential. Protein engineering, design \& selection : PEDS 24, 589-596.

Daffe, M., Papa, F., Laszlo, A., David, H.L., 1989. Glycolipids of recent clinical isolates of Mycobacterium tuberculosis: chemical characterization and immunoreactivity. J. Gen. Microbiol. 135, 2759-2766.

De Libero, G., Mori, L., 2014. The T-cell response to lipid antigens of Mycobacterium tuberculosis. Front. Immunol. 5, 219.

Eckstein, T.M., Chandrasekaran, S., Mahapatra, S., McNeil, M.R., Chatterjee, D., Rithner, C.D., Ryan, P.W., Belisle, J.T., Inamine, J.M., 2006. A major cell wall lipopeptide of Mycobacterium avium subspecies paratuberculosis. The Journal of biological chemistry $281,5209-5215$. 
Ganusov, V.V., Klinkenberg, D., Bakker, D., Koets, A.P., 2015. Evaluating contribution of the cellular and humoral immune responses to the control of shedding of Mycobacterium avium spp. paratuberculosis in cattle. Vet. Res. 46, 62.

Gurung, R.B., Purdie, A.C., Begg, D.J., Whittington, R.J., 2012a. In silico identification of epitopes in Mycobacterium avium subsp. paratuberculosis proteins that were upregulated under stress conditions. Clinical and vaccine immunology : CVI 19, 855864.

Gurung, R.B., Purdie, A.C., Begg, D.J., Whittington, R.J., 2012b. In silico screened Mycobacterium avium subsp. paratuberculosis (MAP) recombinant proteins upregulated under stress conditions are immunogenic in sheep. Vet. Immunol. Immunopathol. 149, 186-196.

Gurung, R.B., Purdie, A.C., Whittington, R.J., Begg, D.J., 2014. Cellular and humoral immune responses in sheep vaccinated with candidate antigens MAP2698c and MAP3567 from Mycobacterium avium subspecies paratuberculosis. Frontiers in cellular and infection microbiology 4, 93.

Holbert, S., Branger, M., Souriau, A., Lamoureux, B., Ganneau, C., Richard, G., Cochard, T., Tholoniat, C., Bay, S., Winter, N., Moyen, J.L., Biet, F., 2015. Interferon gamma response to Mycobacterium avium subsp. paratuberculosis specific lipopentapeptide antigen L5P in cattle. Res. Vet. Sci. 102, 118-121.

Hughes, V., Denham, S., Bannantine, J.P., Chianini, F., Kerr, K., May, L., McLuckie, J., Nath, M., Stevenson, K., 2013. Interferon gamma responses to proteome-determined specific recombinant proteins: potential as diagnostic markers for ovine Johne's disease. Vet. Immunol. Immunopathol. 155, 197-204. 
Jungersen, G., Huda, A., Hansen, J.J., Lind, P., 2002. Interpretation of the gamma interferon test for diagnosis of subclinical paratuberculosis in cattle. Clin. Diagn. Lab. Immunol. 9, 453-460.

Khoo, K.H., Jarboe, E., Barker, A., Torrelles, J., Kuo, C.W., Chatterjee, D., 1999. Altered expression profile of the surface glycopeptidolipids in drug-resistant clinical isolates of Mycobacterium avium complex. The Journal of biological chemistry 274, 97789785.

Lybeck, K.R., Storset, A.K., Djonne, B., Valheim, M., Olsen, I., 2011. Faecal shedding detected earlier than immune responses in goats naturally infected with Mycobacterium avium subsp. paratuberculosis. Res. Vet. Sci. 91, 32-39.

Magombedze, G., Eda, S., Stabel, J., 2015. Predicting the Role of IL-10 in the Regulation of the Adaptive Immune Responses in Mycobacterium avium Subsp. paratuberculosis Infections Using Mathematical Models. PLoS One 10, e0141539.

Marcant, A., Denys, A., Melchior, A., Martinez, P., Deligny, A., Carpentier, M., Allain, F., 2012. Cyclophilin B attenuates the expression of TNF-alpha in lipopolysaccharidestimulated macrophages through the induction of B cell lymphoma-3. J. Immunol. $189,2023-2032$.

Mercier, P., Freret, S., Laroucau, K., Gautier, M-P., Brémaud, I., Bertin, C., Rossignol, C., Souriau, A., Guilloteau, L.A., 2016. A longitudinal study of the Mycobacerium avium subspecies paratuberculosis infection status in young goats and their mothers. Vet. Microbiol. 195, 9-16.

Mikkelsen, H., Aagaard, C., Nielsen, S.S., Jungersen, G., 2011. Review of Mycobacterium avium subsp. paratuberculosis antigen candidates with diagnostic potential. Vet. Microbiol. 152, 1-20. 
Mon M.L., Viale M., Baschetti G., Alvarado Pinedo F., Gioffre A., Travería G., Willemsen P., Bakker D., Romano M.I., 2012. Search for Mycobacterium avium subspecies paratuberculosis antigens for the diagnosis of paratuberculosis. Vet. Med. Int. 2012, 860362. doi:10.1155/2012/860362

Mukherjee, R., Chatterji, D., 2012. Glycopeptidolipids: immuno-modulators in greasy Mycobacterial cell enveloppe. Life. 64:215-225.

Nielsen, S.S., Toft, N., 2008. Ante mortem diagnosis of paratuberculosis: a review of accuracies of ELISA, interferon-gamma assay and faecal culture techniques. Vet. Microbiol. 129, 217-235.

Olivier, M., Foret, B., Le Vern, Y., Guilloteau, L.A., 2012. Capacities of migrating CD1b+ lymph dendritic cells to present Salmonella antigens to naive T cells. PLoS One 7, e30430.

Olsen, I., Tryland, M., Wiker, H.G., Reitan, L.J., 2001. AhpC, AhpD, and a secreted 14kilodalton antigen from Mycobacterium avium subsp. paratuberculosis distinguish between paratuberculosis and bovine tuberculosis in an enzyme-linked immunosorbent assay. Clin. Diagn. Lab. Immunol. 8, 797-801.

Osterstock, J.B., Fosgate, G.T., Norby, B., Manning, E.J., Collins, M.T., Roussel, A.J., 2007. Contribution of environmental mycobacteria to false-positive serum ELISA results for paratuberculosis. J. Am. Vet. Med. Assoc. 230, 896-901.

Palma-Nicolas, JP., Hernandez-Pando, R., Segura, E., Ibarra-Sanchez, MJ., Estrada-Garcia, I., Zentela-Dehesa, A., Lopez-Marin, LM., 2010. Mycobacterial di-O-acyl trehalose inhibits Th-1 cytokine gene expression in murine cells by down-modulation of MAPK signaling. Immunobiology. 215, 143-152. 
Papa, F., Cruaud, P., Luquin, M., Thorel, M.F., Goh, K.S., David, H.L., 1993. Isolation and characterization of serologically reactive lipooligosaccharides from Mycobacterium tuberculosis. Res. Microbiol. 144, 91-99.

Patel, B.K., Banerjee, D.K., Butcher, P.D., 1991. Characterization of the heat shock response in Mycobacterium bovis BCG. J. Bacteriol. 173, 7982-7987.

Pradenas, M., Jara, M.C., Hernandez, N., Zambrano, A., Collins, M.T., Kruze, J., 2009. Antibody recognition to secreted proteins of Mycobacterium avium subsp. paratuberculosis in sera from infected ruminants. Vet. Microbiol. 138, 378-383.

Ribeiro-Guimaraes, M.L., Pessolani, M.C., 2007. Comparative genomics of mycobacterial proteases. Microb. Pathog. 43, 173-178.

Stabel, J.R., 1996. Production of gamma-interferon by peripheral blood mononuclear cells: an important diagnostic tool for detection of subclinical paratuberculosis. Journal of veterinary diagnostic investigation : official publication of the American Association of Veterinary Laboratory Diagnosticians, Inc 8, 345-350.

Stabel, J.R., 2000. Transitions in immune responses to Mycobacterium paratuberculosis. Vet. Microbiol. 77, 465-473.

Storset, A.K., Berg, I., Djonne, B., 2005. Evaluation of the gamma interferon test for diagnosis of paratuberculosis in goats. Vet. Immunol. Immunopathol. 107, 87-94.

Thirunavukkarasu, S., Plain, K.M., Eckstein, T.M., de Silva, K., Whittington, R.J., 2013. Cellular and humoral immunogenicity of Mycobacterium avium subsp. paratuberculosis specific lipopentapeptide antigens. Res. Vet. Sci. 95, 123-129.

Whittington, R.J., Sergeant, E.S., 2001. Progress towards understanding the spread, detection and control of Mycobacterium avium subsp paratuberculosis in animal populations. Aust. Vet. J. 79, 267-278. 
Willemsen, P.T., Westerveen, J., Dinkla, A., Bakker, D., van Zijderveld, F.G., Thole, J.E., 2006. Secreted antigens of Mycobacterium avium subspecies paratuberculosis as prominent immune targets. Vet. Microbiol. 114, 337-344.

Wynne, J.W., Shiell, B.J., Colgrave, M.L., Vaughan, J.A., Beddome, G., Michalski, W.P., 2012. Production and proteomic characterisation of purified protein derivative from Mycobacterium avium subsp. paratuberculosis. Proteome science 10, 22. 


\section{Figure legends}

Figure 1. Comparison of goat IFN- $\gamma$ detection with different IFN- $\gamma$ ELISA a) Correlation between the commercial bovine IFN- $\gamma$ EASIA kit and our IFN- $\gamma$ ELISA when PPDa was used as the reference antigen in IGRA. b) Correlation between our IFN- $\gamma$ ELISA when PPDa or PPDj were used as the reference antigen in IGRA.

Figure 2. Kinetics of IFN- $\gamma$ response to PPDa and PPDj in young goats. Kids were tested monthly from 4 months old for 19 months including a pregnancy (from 8 to 12 months old). The individual status of MAP infection of goats was determined over this period of study and classified as infected shedder (IS), infected and non-shedder (INS) and non-infected (NI). Results are expressed as the number of positive animals.

Figure 3. Kinetics of IFN- $\gamma$ response to new MAP antigens in young goats. Kids $(n=45)$ were tested monthly for IFN- $\gamma$ response to 10 recombinant proteins, PPDa and PPDj from 4 to 19 months of age including a pregnancy (from 8 to 12 months old). The individual status of MAP infection of goats was defined over this period of study and classified as a) non-infected (NI), b) infected and non-shedder (INS), and c) infected shedder (IS). Results are expressed as the number of positive animals. 
Figure 4. Expression of sensitivity (Se) and specificity (Sp) of IFN- $\gamma$ ELISA using new MAP antigens in young goats, calculated at 6 and 20 months of age, for the 10 antigens tested, PPDa and PPDj, for infected shedders (IS) and infected non-shedders (INS). Results are expressed for a) infected (IS + INS), b) INS, c) IS goats.

PPDa and PPDj

MAP antigens giving the highest Se and Sp

Figure 5. Expression of Se and Sp of IFN- $\gamma$ ELISA using new MAP antigens in adult goats. Results are shown for the 10 antigens tested, PPDa and PPDj in infected shedders (IS) and in infected non-shedders (INS) pregnant two year-old goats $(\mathrm{n}=20)$, and expressed for a) infected shedder (IS + INS), b) INS, c) IS goats.

Figure 6. IFN- $\gamma$ response to new MAP antigens in paratuberculosis-free goats. IFN- $\gamma$ response was tested using the 10 antigens, PPDa and PPDj in $\mathbf{a})$ an indoor herd ( $\mathrm{n}=30 ; 1$ to 11 years old) and in $\mathbf{b})$ an outdoor herd ( $\mathrm{n}=36 ; 1$ to 6 years old). IFN- $\gamma$ response is presented separately in c) 1-year-old outdoor goats $(n=18)$ and in $\mathbf{d})$ older outdoor goats $(2$ to 6 years old) $(\mathrm{n}=18)$. Results are expressed as the number of negative animals.

PPDa and PPDj

MAP antigens detecting the highest number of positive goats 
Table 1. Determination of MAP infection status from combined results of diagnostic tests throughout the observation period.

Infection status

(number of goats)

\begin{tabular}{llll}
\hline IFN- $\gamma$ & ELISA & $\begin{array}{l}\text { Faecal } \\
\text { culture }\end{array}$ & Necropsy $^{\mathrm{b}}$
\end{tabular}

Non-infected (NI, $\mathrm{n}=17$ )

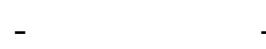

$\mathrm{nd} /-$

Infected and non-shedder

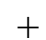

$\mathrm{nd} /-$

$(\mathrm{INS}, \mathrm{n}=40)$

Infected and shedder (IS, $\mathrm{n}=8$ )

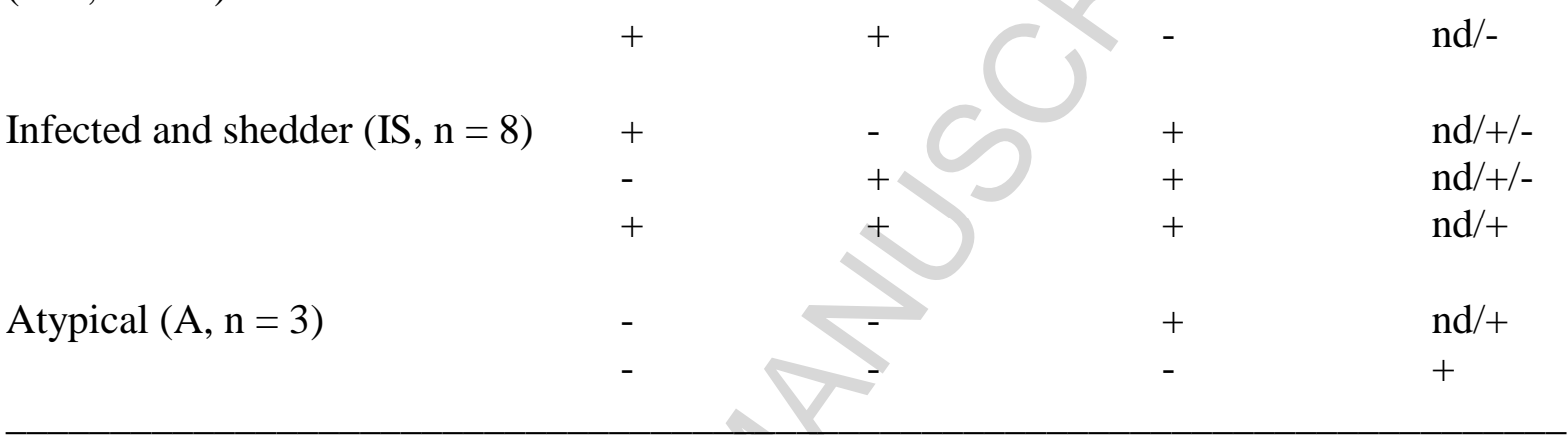

MAP diagnosis $^{\mathrm{a}}$

From Mercier et al. 2016

${ }^{a}$ MAP infection status was determined from the combined results of IFN- $\gamma$ and ELISA tests, faecal culture, and necropsies.

${ }^{\mathrm{b}}$ Necropsies were performed for goats that failed to complete the study. For goats on which post-mortem examinations were not performed, results of necropsy were registered as "not done" (nd). Examinations included macroscopic lesions as well as bacterial detection in tissues by culture or ZN staining. 
Table 2. MAP infection status of goats

\begin{tabular}{llccccc}
\hline Goat age $^{\mathrm{a}}$ & Period of testing & $\begin{array}{l}\text { Number } \\
\text { of animals }\end{array}$ & NI & INS & IS & A \\
\hline $\begin{array}{l}\text { 4 month-old kids } \\
\text { two years of life } \\
\text { including first pregnancy }\end{array}$ & $48^{\mathrm{b}}$ & 11 & 30 & 4 & 3 \\
2 year-old goats & second pregnancy & $20^{\mathrm{b}}$ & 6 & 10 & 4 & 0 \\
Total & & 68 & 17 & 40 & 8 & 3 \\
\hline
\end{tabular}

An MAP infection status was attributed to each animal, after 2 years of monthly diagnosis. $\mathrm{NI}=$ non-infected, INS $=$ infected and non-shedder, $\mathrm{IS}=$ infected shedder, $\mathrm{A}=$ atypical, $\mathrm{NC}=$ non-classified

${ }^{\mathrm{a}}$ age at the beginning of the study

bonly NI, INS and IS goats (45 kids and 20 adult goats) were used for the MAP antigen screening, atypical and non-classified goats were excluded from the analysis. 
Table 3. Antigen candidates tested for IFN- $\gamma$ response to MAP

\begin{tabular}{|c|c|c|c|}
\hline Antigen & $\begin{array}{l}\text { Size } \\
(\mathrm{kDa})\end{array}$ & Characteristic & Presence in mycobacteria ${ }^{\mathrm{a}}$ \\
\hline \multicolumn{4}{|l|}{ Proteins } \\
\hline Map1653 & 16.7 & Putative thiol peroxidase, Tpx & MAV_2770 (99.4\%), Rv1932 (84.1\%), Mb1967 (94.1\%) \\
\hline Map1589c & 21.6 & Alkyl hydroperoxid reductase C, AhpC & MAV_2839 (99.5\%), Rv2428 (89.7\%), Mb2454 (89.7\%) \\
\hline Map3527 & 35.7 & Serine protease PepA & MAV_5187 (86.1\%), Rv0125 (71.8\%), Mb0130 (71.8\%) \\
\hline Map3936 & 56.6 & Heat shock protein 65 , GroEL & MAV_4707 (90.6\%), Rv0440 (85.3\%), Mb0448 (85.3\%) \\
\hline Map 0210c & 30.7 & Secreted PirG protein & MAV_0207 (66.9\%), Rv3810 (45.9\%), Mb3840 (45.9\%) \\
\hline Map 3651c & 44.0 & Acyl-CoA deshydrogenase FadE3_2 & MAV_4958 (93.7\%), Rv0215c (81.3\%), Mb0221c (82.1\%) \\
\hline Map 2020 & 26.9 & Putative hydrolase & MAV_2169 (91.5\%), Rv1758 (53.6\%), Mb1788 (54.8\%) \\
\hline Map $1693 \mathrm{c}$ & 18.3 & Peptidyl-propyl cis-trans isomerase & MAV_2725 (75.1\%), No homologues for M.tub or M. bov \\
\hline Map0209c & 56.5 & CSP involved in peptidoglycan metabolism & MAV_0206 (92.4\%), Rv3811 (74.9\%), Mb3841 (74.9\%) \\
\hline Map4000c & 11.7 & Putative ESAT-6 like protein CFP10 & MAV_4642 (100\%), Rv3905c (67.3\%), Mb3935c (72.7\%) \\
\hline Map3840 & 66.5 & Heat shock protein 70 , DnaK & MAV_4808 (94.6\%), Rv0350 (89.6\%), Mb0358 (89.6\%) \\
\hline Map1889c & 28.0 & Wag31 & MAV_2345 (84.4\%), Rv2145c (78.8\%), Mb2169c (78.8\%) \\
\hline Map 1050c & 32.8 & Isomerase PpiB & MAV_3462 (76.3\%), Rv2582(63\%), Mb2613 (63\%) \\
\hline Map 2167c & 16.8 & Unknown & MAV_2019(74.4\%), Rv2376c (79.6\%), Mb2397c (79.6\%) \\
\hline Map 0211 & 46.0 & UDP-galactopyranose mutase Glf & MAV_0208 (95\%), Rv3809c (89.3\%), Mb3839c (89.3\%) \\
\hline Map 2513c & 36.6 & Putative oxydoreductase & MAV_1409 (96.2\%), No homologues for M.tub or M. bov \\
\hline \multicolumn{4}{|l|}{ Lipids } \\
\hline LOS & & Lipooligosaccharide in cell envelope & in most mycobacteria \\
\hline Para-LP-01 ${ }^{\mathrm{b}}$ & & Pentapeptolipid, major cell wall lipopeptide & in Map (not in Maa, M.tub or M.bovis) \\
\hline $\mathrm{LPx}^{\mathrm{b}}$ & & Pentapeptolipid, major cell wall lipopeptide & in Map (not in Maa, M.tub or M.bovis) \\
\hline DAT & & Di-acyl-trehalose in cell envelope & in most mycobacteria \\
\hline GPL4 & & glycopeptolipid serotype 4 & in Maa (not in Map, M.tub or M.bovis) \\
\hline
\end{tabular}

${ }_{\mathrm{a}}^{\mathrm{a}}$ M. avium subsp. avium 104 (MAV), M. tuberculosis H37Rv (Rv), M. bovis subsp. bovis AF2122/97 (Mb)

${ }^{\mathrm{b}}$ Para-LP-01 and its carboxylic acid version LPx.

Antigens only tested for the first year of kid life. 
Table 4. Potential antigen candidates for IFN- $\gamma$ assay at different stages of MAP infection in goats

\begin{tabular}{lccccccc}
\hline Antigen & \multicolumn{3}{c}{6 month-old } & \multicolumn{2}{c}{20 month-old } & \multicolumn{2}{c}{$>$ year-old (pregnancy period) } \\
& IS & INS & IS & INS & IS & INS \\
& & & & & - & - \\
Map1653 & $+{ }^{1}$ & $+{ }^{1}$ & $(+)$ & - & - & - \\
Map1589c & $+{ }^{1}$ & $+{ }^{1}$ & + & + & - & - \\
Map3527 & + & + & + & + & - & - \\
Map3936 & + & + & - & - & - & - \\
Map0210c & $(+)$ & - & + & + & + & $(+)$ \\
Map3651c & + & - & + & - & + & $(+)$ \\
Map2020 & + & + & $(+)$ & $(+)$ & - & - \\
Map4000c & + & + & - & - & - & - \\
Map1050c & + & - & + & - & + & - \\
Map3840 & $(+)$ & - & $(+)$ & - & & \\
\hline
\end{tabular}

IS = infected shedder, INS = infected and non-shedder ${ }^{1}$ non-specific response

(+) Se lower than the other antigens 
Figure 1
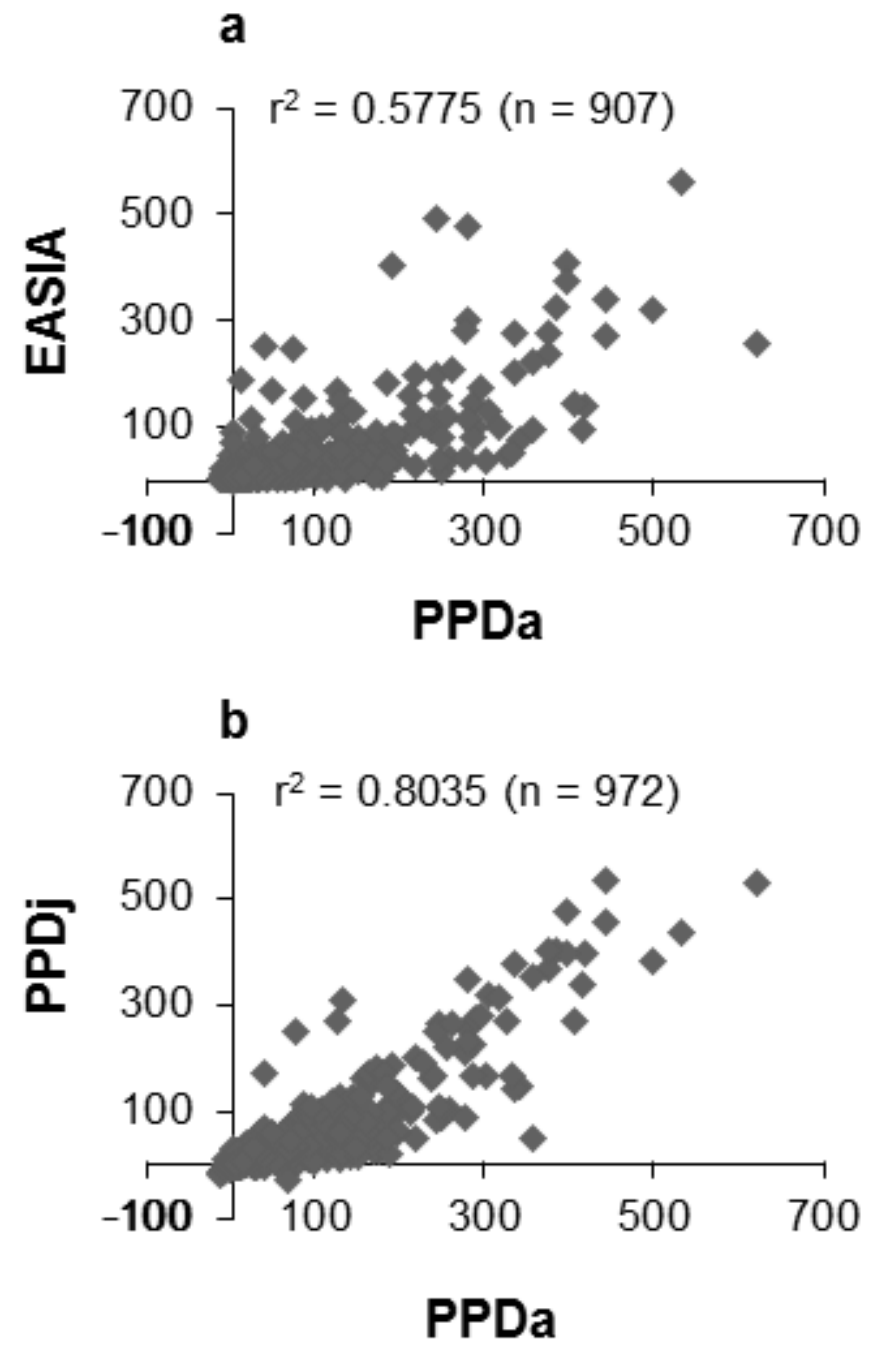
Figure 2

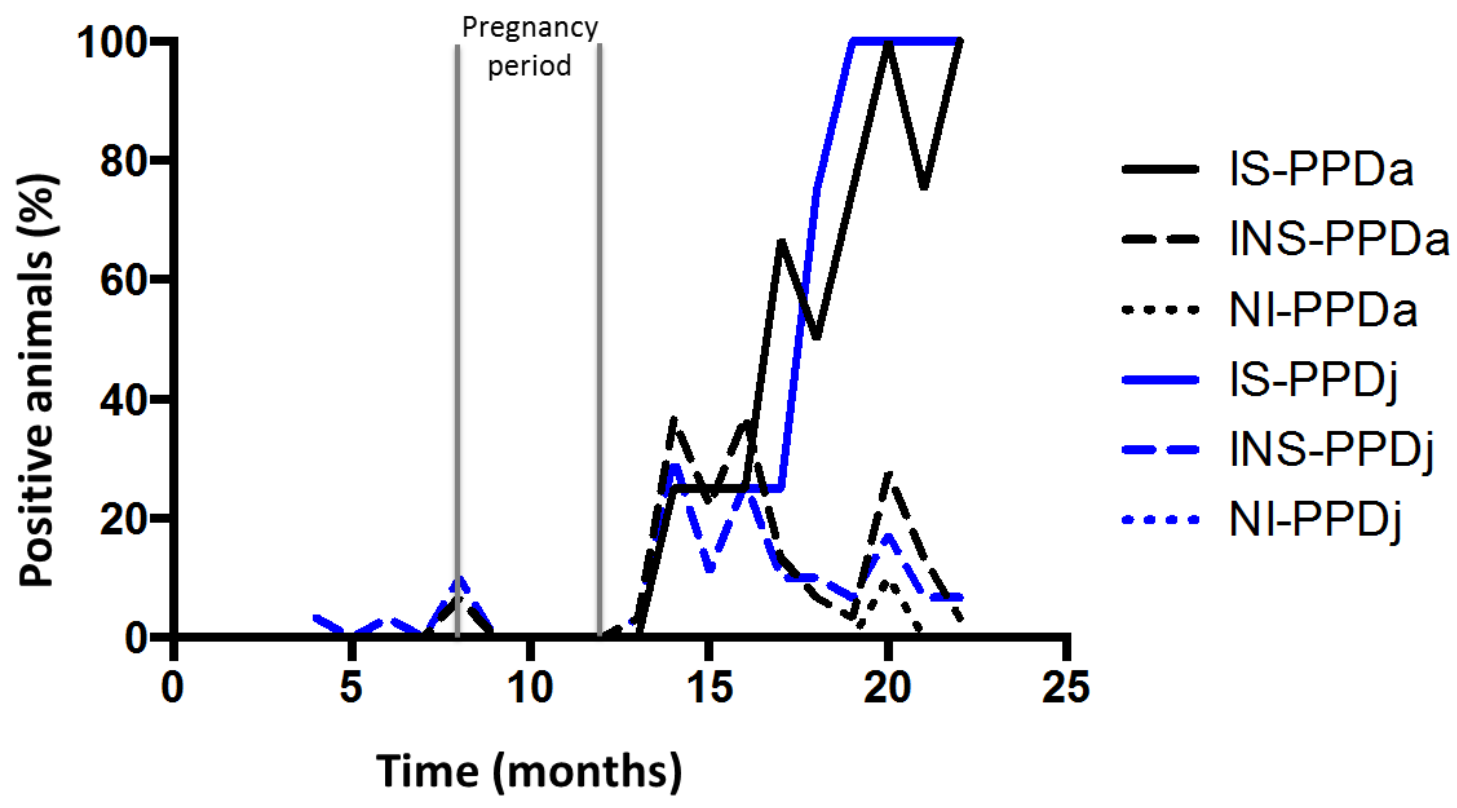


Figure 3
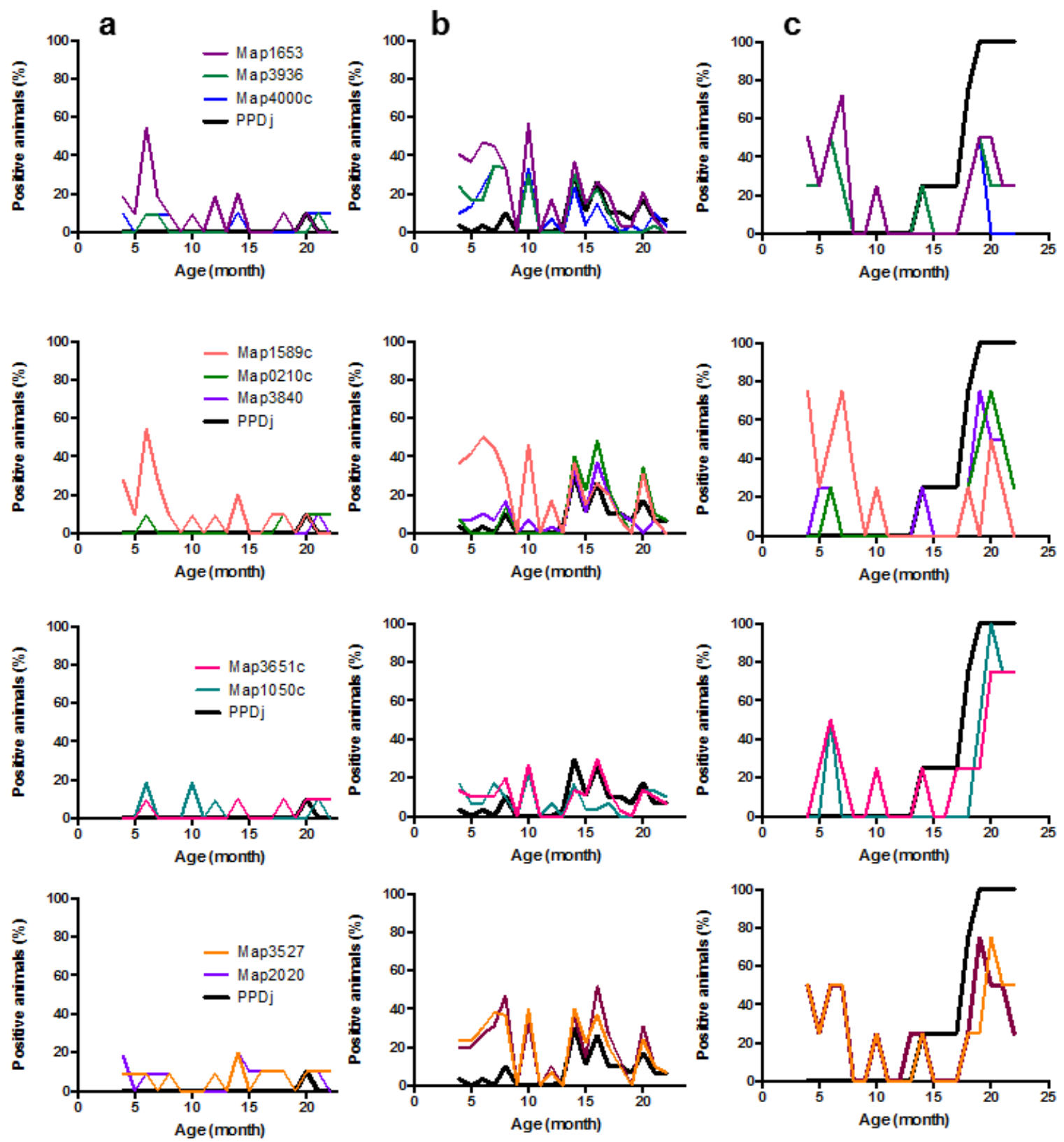
Figure 4

6-month-old
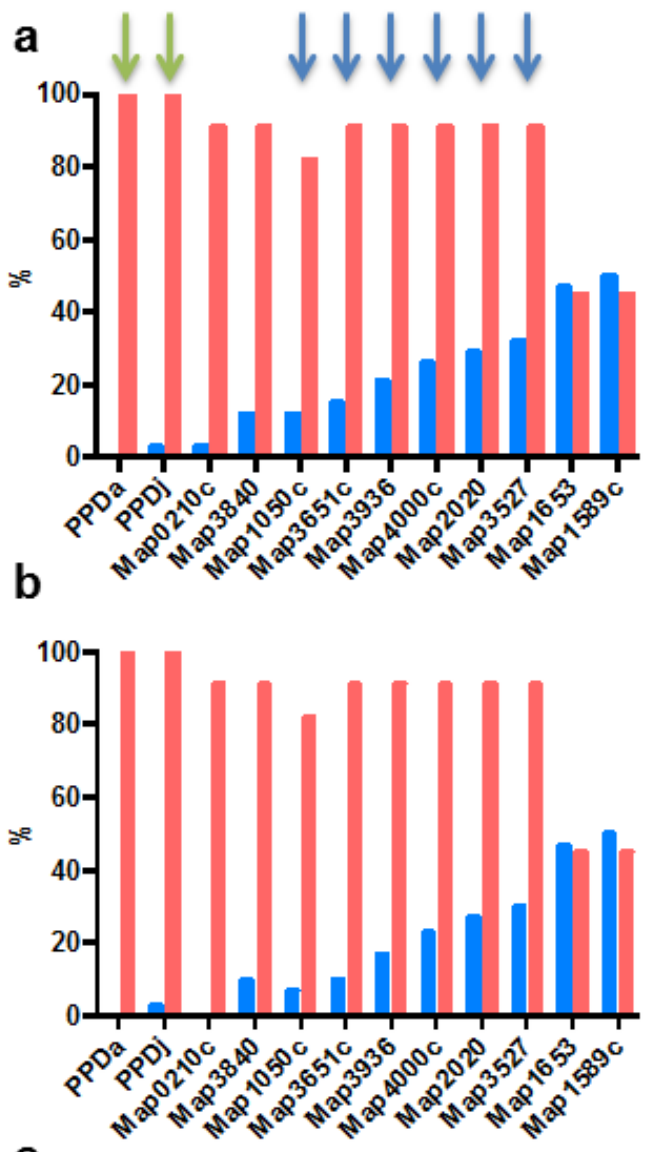

C

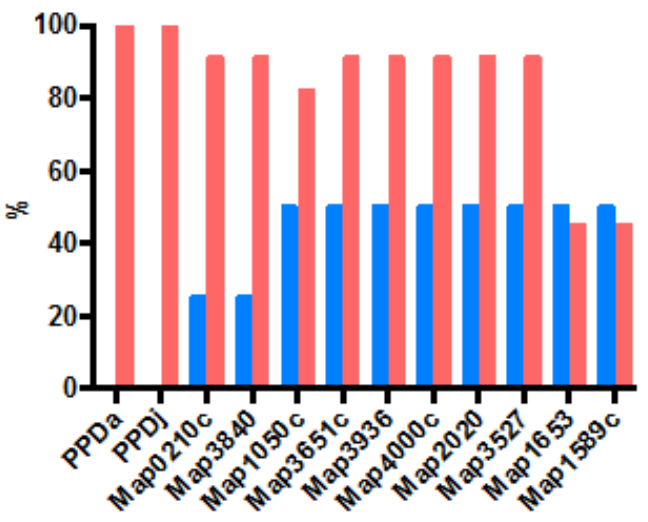

20-month-old
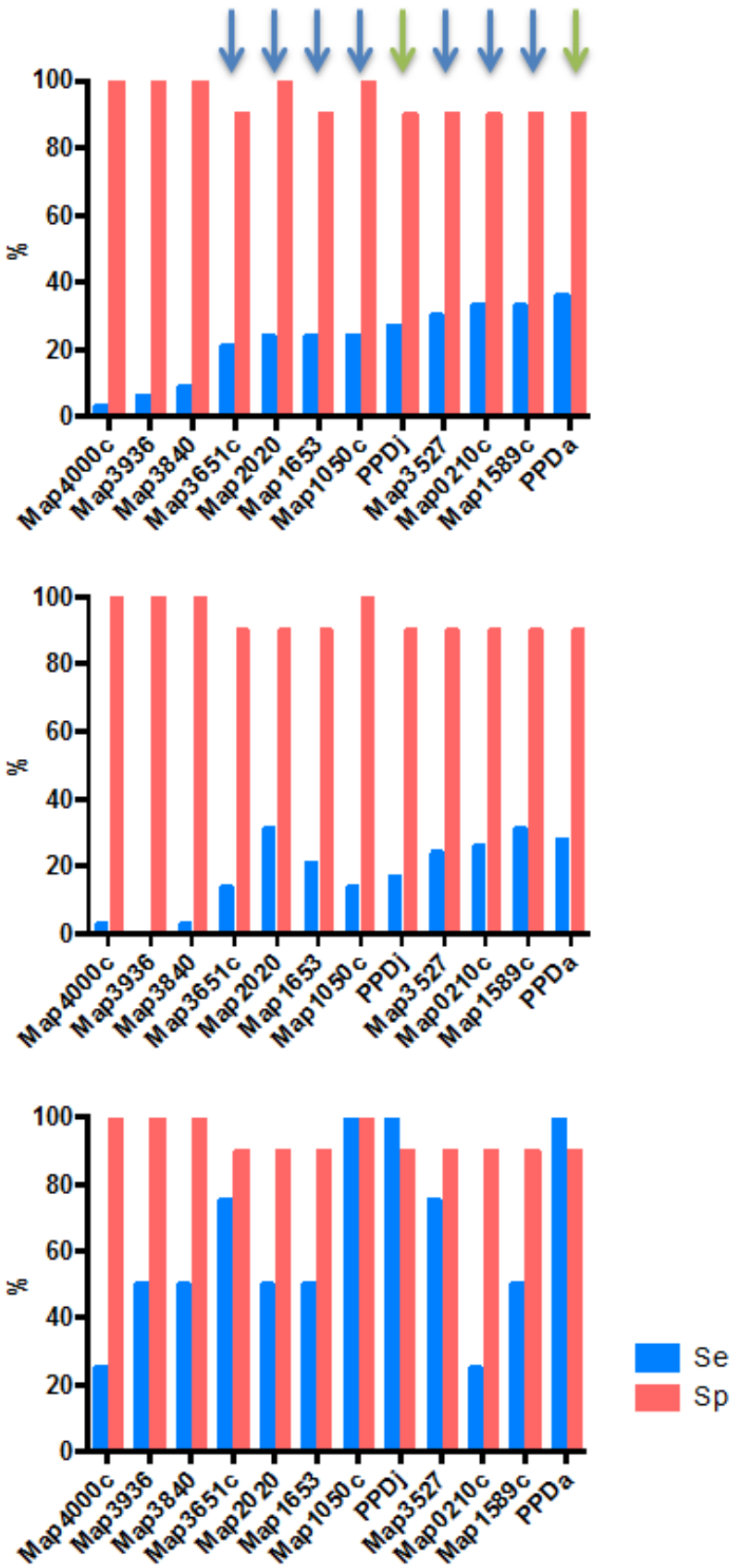
Figure 5
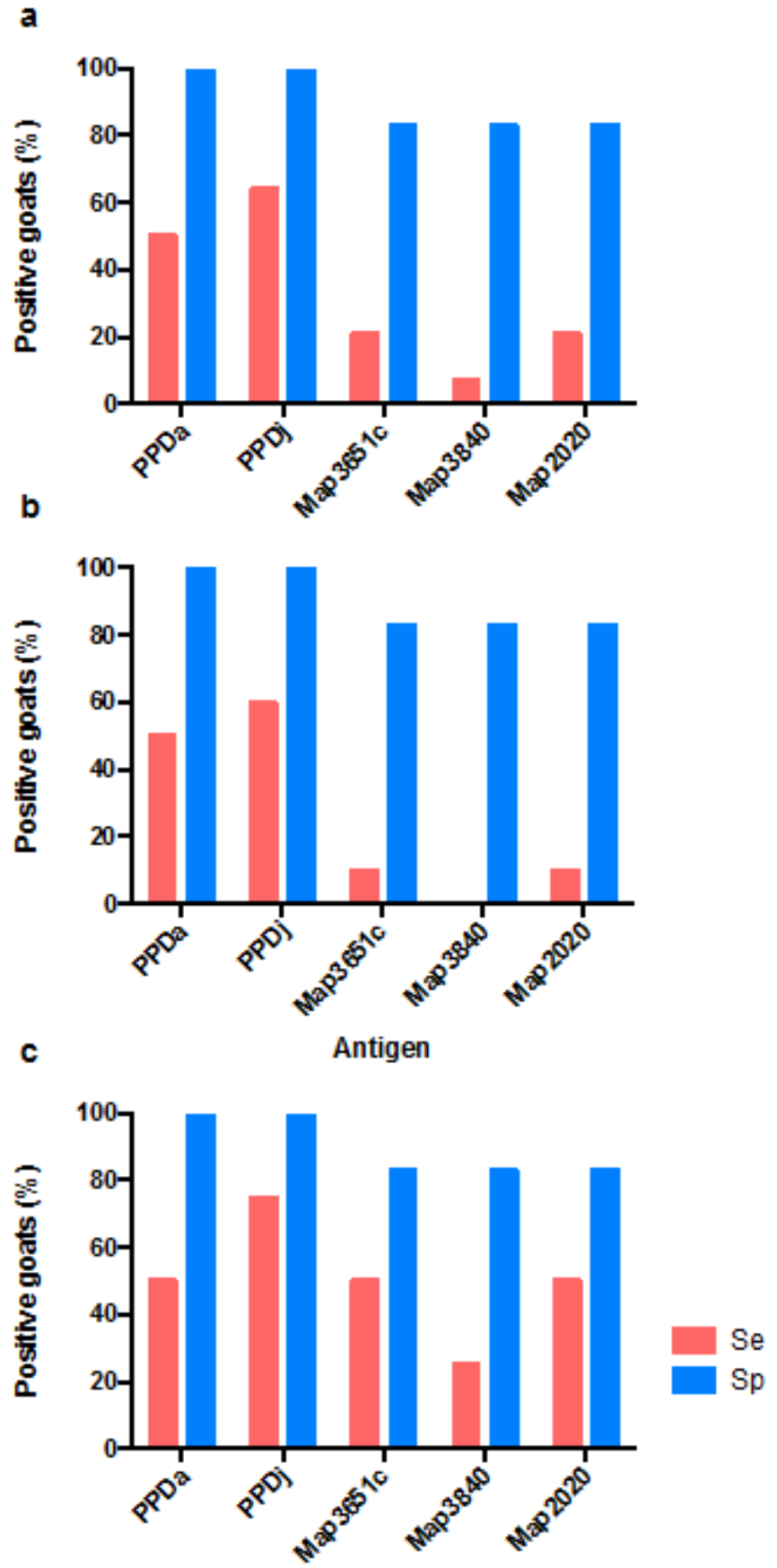


\section{Figure 6}
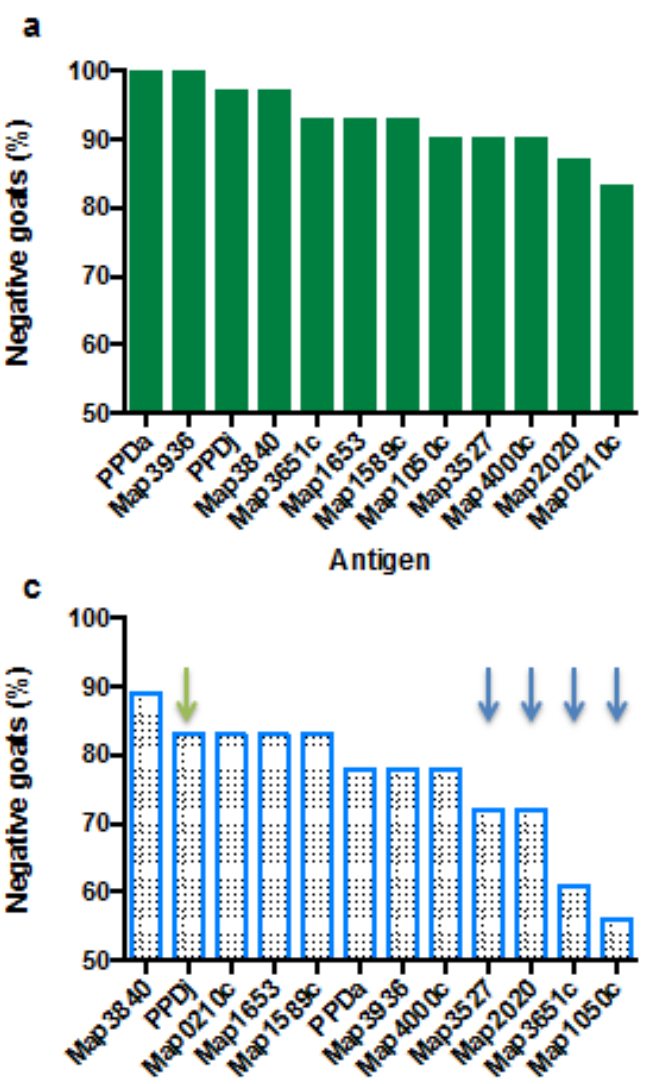

Antigen

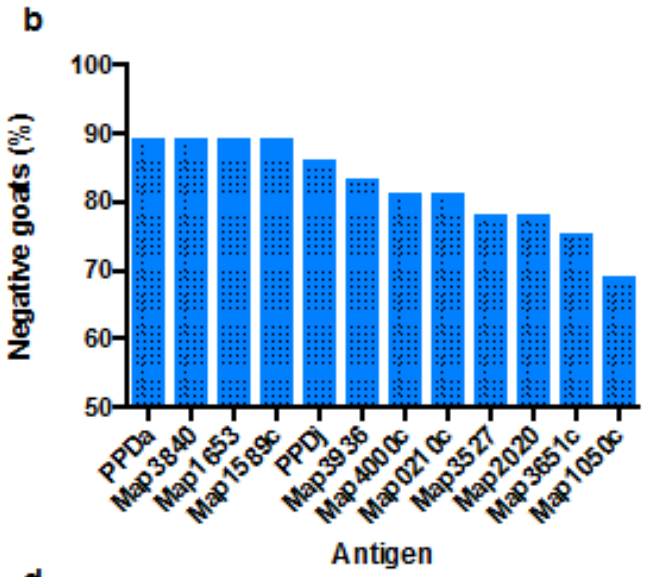

d

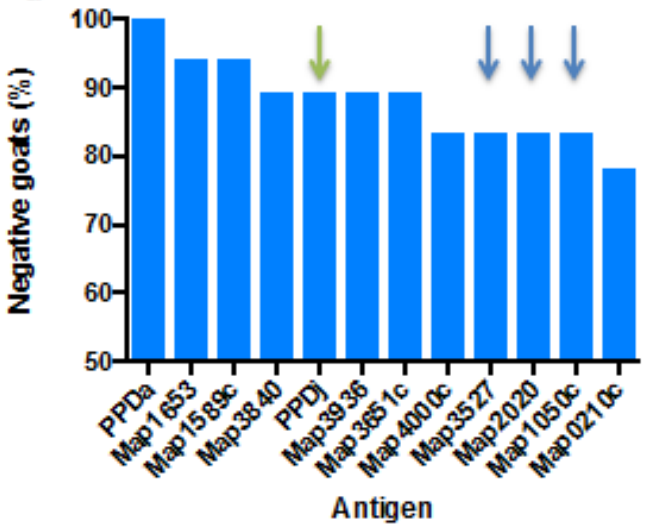

